\title{
Hepatitis B virus DNA polymerase gene polymorphism based prediction of genotypes in chronic HBV patients from Western India.
}

\author{
Yashwant G Chavan ${ }^{1,2}$, Sharad R Pawar ${ }^{2}$, Minal Wani ${ }^{1}$, Amol D Raut ${ }^{2}$, Rabindra N Misra ${ }^{1,3}$
}

1. Dr. D Y Patil Biotechnology and Bioinformatics Institute, Tathwade, Pune 411033. Dr. D Y Patil Vidyapeeth, Sant Tukaram Nagar, Pimpri, Pune 411018. Maharashtra, India.

2. Medical Genetics, geneOmbio Technologies Private Limited, Baner, Pune 411045. Maharashtra, India.

3. Department of Microbiology, Dr. D Y Patil Medical College, Dr. D Y Patil Vidyapeeth, Sant Tukaram Nagar, Pimpri, Pune 411018. Maharashtra, India.

\begin{abstract}
Background: Hepatitis B Virus (HBV) infection is one of the major causes of liver cirrhosis, hepatocellular carcinoma and deaths due to the acute or chronic consequences worldwide. HBV is distributed into various genotypes based on nucleic acid sequence variation.

Objectives: To develop a method of HBV genotyping and drug resistance interpretation using partial sequencing of polymerase gene.

Methods: This study was performed on $98 \mathrm{HBV}$ infected patients' serum samples from Western India. A nested PCR protocol was designed for amplification of pol gene from HBV genome and Sanger's sequencing of the gene fragment. Sequences were aligned with HBV reference sequences for phylogenetic analysis and for characterization of genetic diversity. Drug resistance mutations were screened using HBVSeq program from Stanford University.

Results: Distribution of HBV genotypes showed predominance of genotype D, circulating in $76(77.55 \%)$ patients $(\mathrm{p}<0.05)$. Genotypes A and C were less prevalent and were identified in 4 (4.08\%) and 18 (18.37\%) patients, respectively. Anti-retroviral drug resistance mutations were not detected in any patient.

Conclusion: A method for determination of HBV genotypes using pol gene sequencing which simultaneously detects major drug resistance mutations has been established. HBV genetic diversity may play an important role in treatment decision.

Keywords: Hepatitis B virus, nested PCR, genotype, sub-genotypes, YMDD mutations.

DOI: https://dx.doi.org/10.4314/ahs.v17i3.19

Cite as: Chavan YG, Pawar SR, Wani M, Raut AD, Misra RN. Hepatitis B Virus DNA polymerase gene polymorphism based prediction of genotypes in chronic HBV patients from Western India. Afri Health Sci. 2017;17(3): 762-772. bttps:// dx.doi.org/10.4314/abs.v17i3.19
\end{abstract}

\section{Introduction}

$\mathrm{HBV}$ infection is a major health care problem with up to 400 million affected persons worldwide and accounts for one million deaths worldwide from cirrhosis, liver failure
Corresponding author:
Yashwant G Chavan
Dr. D Y Patil Biotechnology
and Bioinformatics Institute,
Tathwade, Pune 411033.
Dr. DY Patil Vidyapeeth,
Sant Tukaram Nagar,
Pimpri, Pune 411018.
Maharashtra, India.
Phone +91-9881927528
E-mail: visualyash10@gmail.com

and hepatocellular carcinoma. ${ }^{1} \mathrm{HBV}$ has been broadly classified into eight genotypes, designated as A-H. ${ }^{2}$ This classification is based on inter-genotypic divergence of at least $8 \%$ in the complete nucleotide sequence or more than $4 \%$ in the $\mathrm{S}$ gene. ${ }^{3}$ Evidence from various research studies has suggested that HBV genotypes may play some role in causing different disease profiles in chronic hepatitis $\mathrm{B}(\mathrm{CHB}){ }^{4}$ Among Asians, who constitute greater than $75 \%$ of the worldwide population of individuals with $\mathrm{CHB}$, genotypes $\mathrm{B}$ and $\mathrm{C}$ are the two most common HBV genotypes in Asia and Oceania. ${ }^{5}$ Genotype D is most widely distributed and found in Africa, Europe, Mediterranean countries, India, Indonesia and Nigeria. ${ }^{6}$ Correlation of genotypes with severity of infection has also been established. Researchers have found the association of genotype $\mathrm{C}$ with more severe liver disease as 
compared to genotype B and higher incidence of HCC in genotype $\mathrm{D}$ infected patients. ${ }^{7}$ In Europe, most patients with genotype D are reported to have acute hepatitis B, while most patients with genotype A have chronic hepatitis B. $^{8}$ Association study in patients on Lamivudine therapy showed that patients with genotype D achieved higher SVR (Sustained viral response) than with genotype $\mathrm{A}$; hence response to therapy is also found to be ruled by genotypes. ${ }^{9}$ Due to these important findings, HBV genotyping has gained immense importance in guiding treatment decisions, improving vaccination, and controlling liver diseases. Various methods of genotyping are available of which sequencing of $\mathrm{S}$ gene was mostly performed in the previous studies. Ying et al., performed semi-nested PCR amplification (using three primers) of pol gene and its sequencing for HBV genotyping in Chinese patients. ${ }^{10}$ In this study, we used nested PCR that uses four primers that results in increased specificity. As this assay is performed on low viral load samples, it also underlines higher sensitivity of nested PCR approach. Advances in molecular biology techniques have led to implementation of real time PCR for detection of HBV genotypes using melting curve analysis. ${ }^{11}$ This study comprises HBV polymerase gene sequencing covering YMDD region which also includes the overlapping $\mathrm{S}$ gene region, it was found that the sequence can be used to identify the genotype of the virus. This genotyping method makes use of Sanger's DNA sequencing technology to sequence HBV DNA polymerase region using different set of primers to amplify the HBV DNA polymerase and overlapping $\mathrm{S}$ gene region. Along with genotyping of Hepatitis $B$ virus, this method also helps in determination of drug resistance mutation in YMDD hot-spot region of DNA polymerase gene.

\section{Materials and methods Study participants}

Four hundred and twenty seven chronic HBV infected patient serum samples were received at Molecular Diagnostic Lab of geneOmbio Technologies Private Limited (Pune, India) during March 2012 to May 2014 from associated hospital laboratories located in Western Indian states of Maharashtra, Goa and Gujrat. This was a retrospective cross-sectional study and all procedures conformed to the ethical guidelines of the 1975 Helsinki Declaration. No personal identification information or other personal identifiers such as address or hospital identification number were recorded to ensure patient confidentiality. This study was approved ethically by the Institutional Review Board (IRB) of geneOmbio Technologies (Approval No. IRB/2012/G-011) and Institutional Biosafety Committee (IBSC) at Dr. D. Y. Patil Vidyapeeth, Pune. The serum samples were collected and stored at $-40^{\circ} \mathrm{C}$ until use.

\section{Inclusion criteria}

Patients with $\mathrm{HBeAg}$ and $\mathrm{HBsAg}$ positive sera confirmed by HbeAg/HbsAg Rapid Test Kit (Medical Biological Services, Italy) and having viral load in the range of 7 $110000000 \mathrm{HBV}$ DNA IU/mL were included. HBV viral load was determined using Roche COBAS TaqMan 48 Kit on COBAS TaqMan 48 Analyzer (Roche Molecular Systems, USA).

\section{Exclusion criteria}

Patients positive for Hepatitis $\mathrm{C}$ virus (HCV) and $\mathrm{Hu}-$ man Immunodeficiency virus (HIV) anti-body test were excluded from the study. Screening for HCV and HIV-1 was done using commercially available HCV TRI DOT and HIV TRI DOT kit (J. MITRA \&Co. Ltd., New Delhi, India). Patients having viral load undetectable or less than $7 \mathrm{HBV}$ DNA IU/mL were also excluded from the study. Of the 427 samples, 140 patients were both HBeAg and HBsAg positive. Thirty eight of these 140 patients had HBV viral load undetectable or less than 7 HBV DNA $\mathrm{IU} / \mathrm{mL}$, therefore were excluded from the study. Four samples were excluded due to co-infection with either HCV or HIV.

Hence this retrospective cross-sectional study examined only a total of 98 (70 males, 28 females, mean age $43.8+$ 11.6 years) patients.

\section{Primer design}

Twenty three full-length HBV sequences representing all of the available HBV genotypes were downloaded from GenBank nucleotide sequence database (http://www. ncbi.nlm.nih.gov). These sequences were selected from list provided by NCBI Genotyping tool (http://www. ncbi.nlm.nih.gov/projects/genotyping) as reference set of sequences for HBV genotyping. Using ClustalW multiple sequence alignment tool the reference sequences were aligned to find the conserved domains. ${ }^{12}$ First round PCR primers YMDDF1 (5'- CAAGGTATGT'TGCCCGTTTG -3') and YMDDR1 (5'-CCCAACTCCTCCCAGTCCTTAA-3') were selected from previously published data. ${ }^{13,14}$ With the help of Primer 3- Online Primer designing tool (http:/ / primer3.ut.ee), we designed 
a nested PCR primer pair YMDDF2 (5' -CTGTATTCCCATCCCATCATC-3') and YMDDR2 (5'-GACCCACAATTCGTTGACATAC-3'). The primers were synthesized at Eurofins Genomics Pvt. Ltd. (Bangalore, India). The amplified fragment of the polymerase gene overlaps slightly with the $\mathrm{S}$ gene. First round PCR primers were expected to generate $1290 \mathrm{bp}$ amplicons whereas the nested PCR primers were expected to generate $409 \mathrm{bp}$ amplicons. Implementation of nested PCR protocol enhances the sensitivity of the assay as it can amplify samples having very low HBV DNA viral load.

\section{DNA isolation, PCR and sequencing of HBV poly- merase gene}

DNA isolation from serum samples was performed using High Pure Viral Nucleic Acid Kit (Roche Molecular Systems, USA) according to the manufacturer's instructions. PCR amplification was performed using Platinum Taq DNA Polymerase (Invitrogen Corporation, USA).

The fragment of the polymerase gene was amplified by nested PCR with two rounds of amplification. Five microliter of DNA isolated from each patient was added to a $20 \mu \mathrm{L}$ PCR mixture. The PCR mix contained 2.5 $\mu \mathrm{l}$ of 10x PCR buffer (100 mM Tris- pH 9.0, $500 \mathrm{mM}$ $\mathrm{KCl}, 15 \mathrm{mM} \mathrm{MgC}_{12}$ and $0.1 \%$ Gelatin), $200 \mu \mathrm{M}$ dNTPs, 1 unit of Platinum Taq DNA polymerase, $20 \mathrm{pM}$ each of YMDDF1 and YMDDR1 primers for first round PCR and sterile nuclease free water to make a final volume of $25 \mu \mathrm{l}$. The first round of amplification was performed with an initial $5 \mathrm{~min}$ denaturing step at $95^{\circ} \mathrm{C}$, followed by 30 cycles of denaturing for $45 \mathrm{~s}$ at $94^{\circ} \mathrm{C}$, annealing for $30 \mathrm{~s}$ at $60^{\circ} \mathrm{C}$, and elongation for $1 \mathrm{~min}$ at $72^{\circ} \mathrm{C}$, with a final extension period of $10 \mathrm{~min}$ at $72^{\circ} \mathrm{C}$. The second round of amplification was performed using $20 \mathrm{pM}$ each of YMDDF2 and YMDDR2 primers, with an initial 5 min denaturing step at $94^{\circ} \mathrm{C}$, followed by 30 cycles of denaturing for $45 \mathrm{~s}$ at $94^{\circ} \mathrm{C}$, annealing for $30 \mathrm{~s}$ at $55^{\circ} \mathrm{C}$, and elongation for $30 \mathrm{~s}$ at $72^{\circ} \mathrm{C}$, with a final extension period of $10 \mathrm{~min}$ at $72^{\circ} \mathrm{C}$. The reaction products of the nested PCR were visualized on a $2 \%(\mathrm{w} / \mathrm{v})$ agarose gel stained with ethidium bromide. Purification of nested PCR products was performed using Purelink PCR product purification kit (Life technologies, USA). Automated DNA sequencing was performed using BigDye Terminator v3.1 Cycle sequencing kit on 3130 Genetic Analyzer (Applied Biosystems, USA). Nucleotide sequences were submitted to NCBI nucleotide sequence database GenBank.

\section{Determination of HBV Genotypes and phylogenetic analysis \\ NCBI HBV genotyping tool (http://www.ncbi.nlm.nih.} gov/projects/genotyping) was used for determination of genotype for each HBV sequence. Nucleotide sequences of 336 bases generated after sequence quality trimming using Chromas Pro 1.34 (Technelysium Pty. Ltd., Queensland, Australia) were used for homology and phylogenetic analysis. Sequences were aligned by using the ClustalW program. Two representative reference sequences from each genotype were used for construction of phylogenetic tree (A: AF418677, X51970; B: D23678, AB073838; C: D50489, Y18855; D: AB090270, AF151735; E: AB032431, X75657; F: AB036905, AB036907; G: AB064313, AB056513 and H: AY090454, AY090457). The alignment was converted in MEGA format using MEGA 6.06 software. 15 The phylogenetic tree was constructed by the Maximum composite likelihood algorithm with a bootstrap test of 1000 replicates.16 Significance of polymerase gene fragment sequence for genotyping was evaluated by phylogenetic analysis of reference sequences of all genotypes $(\mathrm{A}-\mathrm{H})$ obtained from NCBI genotyping tool reference set and GenBank database. This reference set includes total 66 sequences.

\section{Genetic distance}

An analysis of the number of base substitutions per site between the nucleotide sequences (genetic distance (d)) was conducted using the maximum composite likelihood method in MEGA 6.06 for reference sequences from each genotype used for phylogenetic analysis. Analyses were conducted using the Maximum Composite Likelihood model. The differences in the composition bias among sequences were considered in evolutionary comparisons. The analysis involved 16 nucleotide sequences. Similarity matrix was derived from the distance analysis.

\section{Evolutionary substitution rates}

Different genotypes are evolved due to substitution mutations at different sites within the viral genome. ${ }^{17}$ To determine the sites that are highly prone to substitutions, we performed the substitution rate analysis using MEGA 6.06. Substitution pattern and rates were estimated under the Tamura-Nei (1993) model $(+G) \cdot{ }^{18}$ A discrete Gamma distribution was used to model evolutionary rate differences among sites ( 5 categories, $[+\mathrm{G}]) .{ }^{19}$ 


\section{Determination of drug resistance mutations}

Drug resistance interpretation based on mutation in $\mathrm{HBV}$ polymerase gene was inferred by submitting the sequence data to Stanford University database (http://hivdb.stanford.edu/HBV/HBVseq) and Geno2pheno (hbv) resistance prediction tool (http://hbv.geno2pheno.org) (Max Planck Institute)

\section{Statistical analysis}

Clinical characteristics, mean and frequency of genotyping data were analysed using a SPSS statistics (2014) and
Microsoft Excel (2013). Descriptive statistics are presented as proportions, means \pm standard deviation, and medians with interquartile range. Comparative analyses were performed using the Student's t-test and Chi square test. A P value of less than 0.05 was considered significant.

\section{Results}

Clinical characteristics of study patients infected with HBV are provided in Table 1. All the patients were from state of Maharashtra geographically located in Western India. Mean HBV viral load of study samples was $4.46+$ $1.77 \mathrm{HBV}$ DNA IU/mL.

Table 1. Clinical characteristics of study patients infected with Hepatitis B Virus

\begin{tabular}{|l|l|}
\hline Variables & Population $(\mathbf{n}=\mathbf{9 8})$ \\
\hline Age, years & $43.8 \pm 11.6$ \\
\hline Male/Female, n (\%) & $70 / 28(71.43 \% / 28.57 \%)$ \\
\hline HBsAg, positive & $98(100 \%)$ \\
\hline HBeAg, positive & $98(100 \%)$ \\
\hline Serum ALT (U/L) \pm SD & $86.10 \pm 32.54$ \\
\hline HBV DNA positive, $\mathbf{n}(\%)$ & $98(100 \%)$ \\
\hline $\begin{array}{l}\text { HBV viral load, } \log _{\mathbf{1 0}} \text { IU/mL } \\
\text { (range, HBV DNA IU/mL) }\end{array}$ & $4.46 \pm 1.77$ \\
\hline
\end{tabular}

\section{PCR amplification of HBV pol gene}

Hepatitis B Virus DNA isolated from patients generated 409 bp PCR amplification product for pol gene using nested PCR approach (Figure 1). In total, all 98 (100\%) samples were positive for polymerase gene fragments.
Each of these nested PCR reaction products were then sequenced. The nucleotide sequence data was submitted to GenBank, these sequences are available at NCBI nucleotide sequence database with accession number KM076939-KM077016.

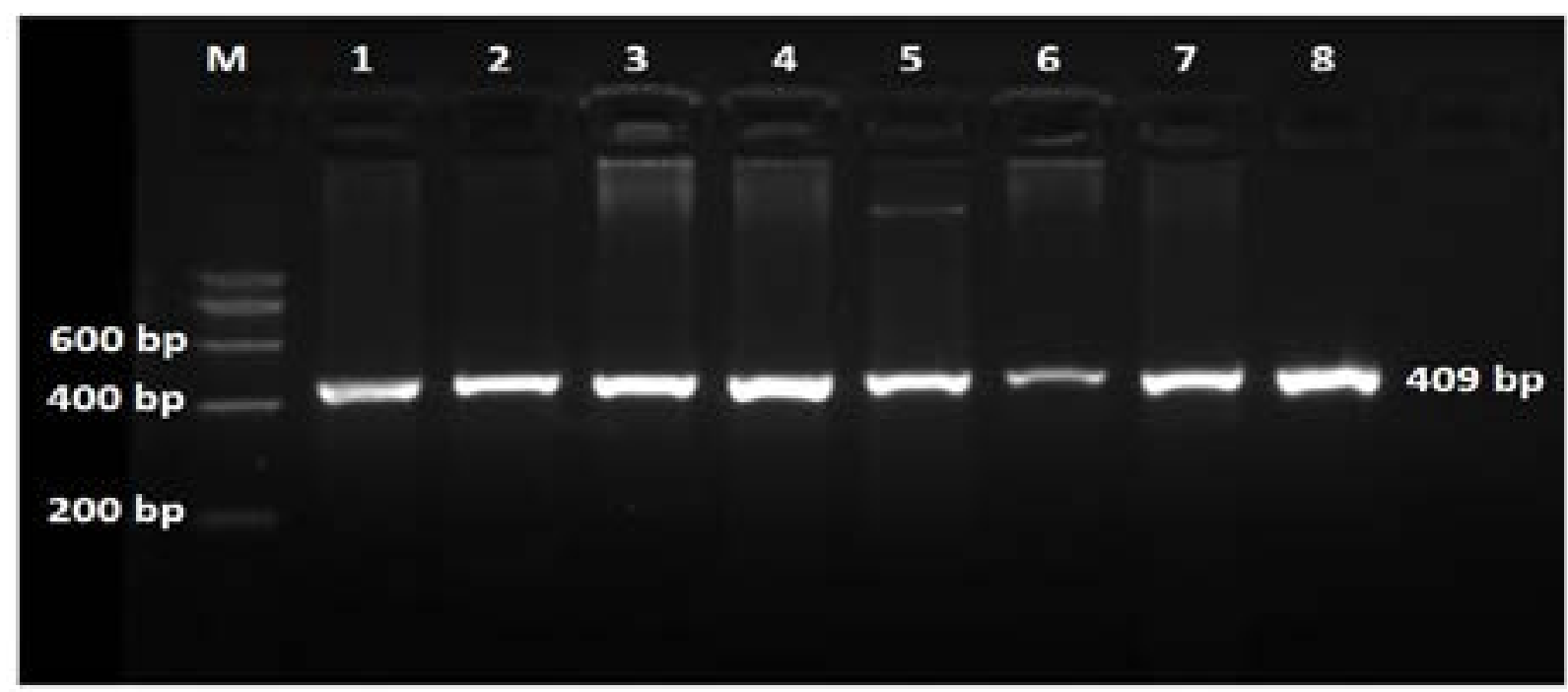

Figure 1. Agarose gel electrophoresis $(2 \% \mathrm{w} / \mathrm{v})$ of the nested PCR products and DNA marker. $200 \mathrm{bp}$ DNA ladder (Lane M), second round of amplification products (Lane 1-8). 
Determination of $\mathrm{HBV}$ genotypes and phylogenetic analysis

Three major genotypes A, C and D were found within the study population as predicted by NCBI genotyping tool for HBV. HBV Genotype D ( $\mathrm{n}=76 ; 77.55 \%)$ was found to be predominant circulating genotype $(\mathrm{p}<0.05)$, followed by $\mathrm{C}(\mathrm{n}=18 ; 18.37 \%)$ and $\mathrm{A}(\mathrm{n}=4 ; 4.08 \%)$ among 98 sequences. Geno2pheno and HBVSeq Programs also determined genotypes and subgenotypes of the sequenc- es. Six sub-genotypes were detected A1, C1, C2, D2, D3 and D4, of which HBV sub-genotypes D2 ( $\mathrm{n}=65$; $66.33 \%$ ). Clinical and demographic characteristics of the study population with respect to sub-genotypes distribution are provided in Table 2. Higher levels of Serum ALT $(110.33+42.54 \mathrm{U} / \mathrm{L})$ were observed in sub-genotypes A1. Genotype prediction from NCBI genotyping tool, Geno2Pheno and HBVSeq produced 100\% similar results.

Table 2. Clinical and demographic characteristic of the study population with respect to sub-genotypes distribution.

\begin{tabular}{|c|c|c|c|c|c|c|}
\hline Genotype & A $(n=4)$ & $\mathrm{C}(n=18)$ & & D $(n=76)$ & & \\
\hline Subgenotype & A1 & C1 & $\mathrm{C2}$ & D2 & D3 & D4 \\
\hline Number of samples (\%) & $4(4.08)$ & $7(7.14)$ & $11(11.22)$ & $65(66.33)$ & $1(1.02)$ & $10(10.20)$ \\
\hline Male/Female (\%) & $\begin{array}{l}4 / 0 \\
(100 / 0)\end{array}$ & $\begin{array}{l}6 / 1 \\
(85.71 / 14.29)\end{array}$ & $\begin{array}{l}6 / 5 \\
(54.55 / 45.45)\end{array}$ & $\begin{array}{l}45 / 20 \\
(69.23 / 30.77)\end{array}$ & $\begin{array}{l}1 / 0 \\
(100 / 0)\end{array}$ & $\begin{array}{l}8 / 2 \\
(80 / 20)\end{array}$ \\
\hline Age, years (range) & $38.0 \pm 11.69$ & $41.57 \pm 5.32$ & $43.36 \pm 8.49$ & $45.12 \pm 12.65$ & $49.0 \pm 0.00$ & $39.3 \pm 10.88$ \\
\hline $\begin{array}{l}\text { Serum } \\
\text { (range) }\end{array} \quad$ ALT $\quad(\mathbf{U} / \mathbf{L})$ & $110.33 \pm 42.54$ & $96.52 \pm 40.20$ & $86.00 \pm 30.51$ & $82.57 \pm 31.96$ & $72.00 \pm 0.00$ & $93.57 \pm 30.31$ \\
\hline 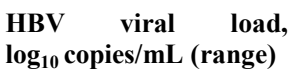 & $4.17 \pm 1.44$ & $4.70 \pm 2.03$ & $3.22 \pm 1.27$ & $4.51 \pm 1.77$ & $3.25 \pm 0.00$ & $5.55 \pm 1.71$ \\
\hline $\begin{array}{l}\text { Common Mutations } \\
(\%)\end{array}$ & $\mathrm{I} 253 \mathrm{~V}(100)$ & $\begin{array}{l}\text { N226H (85), } \\
\text { Q267L (85) }\end{array}$ & $\begin{array}{l}\text { S223A (100), } \\
\text { I224V(100), V253I } \\
(91), \\
\text { Q267H(45), I282V } \\
(45)\end{array}$ & $\begin{array}{l}\text { N248H (49), } \\
\text { D263E (23) }\end{array}$ & $\begin{array}{l}\mathrm{N} 248 \mathrm{H} \\
(100), \mathrm{C} 256 \mathrm{~S} \\
(100)\end{array}$ & $\begin{array}{l}\text { N248H (40), } \\
\text { E271D (60) }\end{array}$ \\
\hline
\end{tabular}

\section{Phylogenetic analysis}

Phylogenetic analysis based on alignment of nucleotide sequences of HBV polymerase gene from 78 study samples and 16 representative reference sequences (NCBI GenBank database) was used to confirm the presence of genotype A, C and D. As evident from phylogenetic tree presented in Figure 2, Genotype A, C and D samples clustered with closest reference sequences of the same genotype. The evolutionary history was inferred using the UPGMA method. Phylogenetic analysis of 66 reference sequences obtained from NCBI GenBank database showed distinct clustering of each genotype proving the significance of use of polymerase gene fragment sequence in HBV genotyping. 


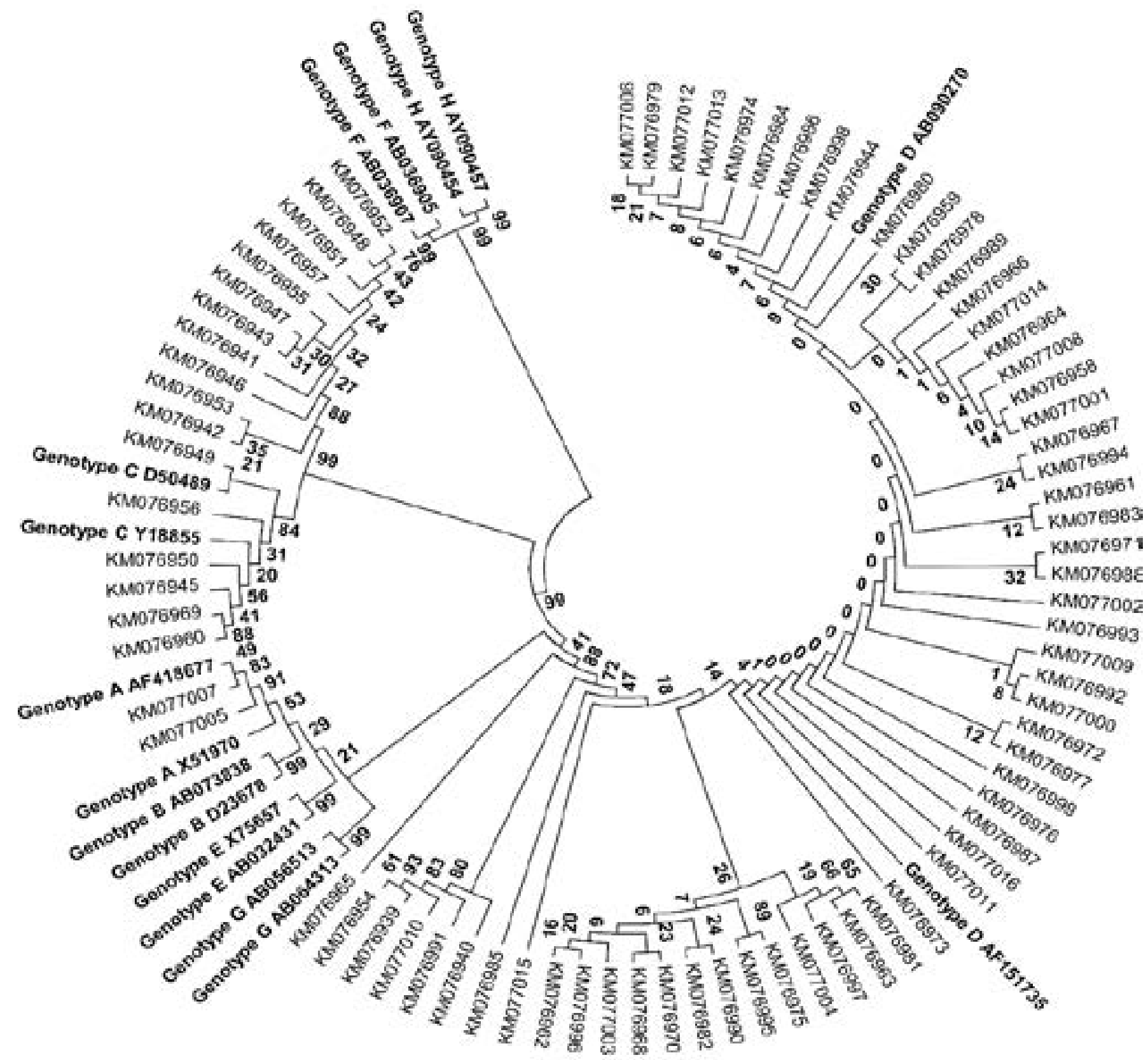

Figure 2. Phylogenetic analysis of Hepatitis B Virus (HBV) based on partial sequence of polymerase gene from 78 study samples and 16 reference sequences representing each genotype. Numbers at respective nodes represent percentage bootstrap values (1000 replicates). The Maximum-Likelihood tree was constructed with a substitution model of Tamura-Nei plus gamma distribution using MEGA software 6.06. As the branch lengths and bootstrap values between various genotype $\mathrm{D}$ sequences were low or zero, the tree has been represented in topology view to make ancestor-descendant relationship clear, hence the scale bar was removed.

Figure 3 shows distinct branches for each genotype sup- ported by significant bootstrap values. 


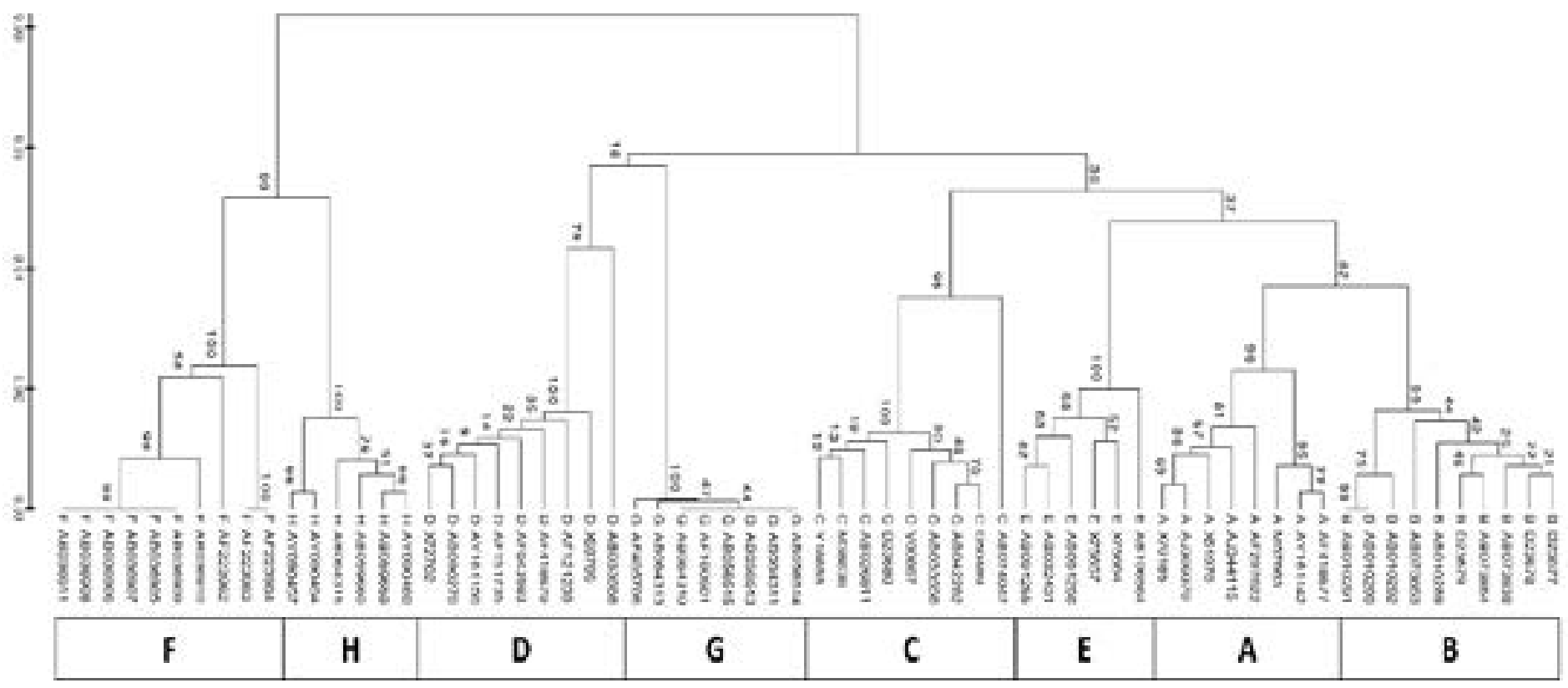

Figure 3. Phylogenetic analysis of 66 reference sequences for polymerase gene obtained from NCBI GenBank database using Maximum-Likelihood Method. Branch reliability is indicated by the percentage of bootstrap values at each node (1,000 replications). The scale bar indicates the number of base substitutions per site.Lower rectangle represent each genotype distributed amongst branches within the tree.

\section{Genetic distances}

When all eight genotypes were compared to each other (Table 3), HBV genotypes showed genetic divergence ranging from 6.7 (genotype A B) to 18.4 (genotype $\mathrm{C} \rightarrow$ $\mathrm{H})$ based on sequence polymorphism in polymerase gene.
The nucleotide sequence similarity ranged from 81.6 (genotype $\mathrm{C} \rightarrow \mathrm{H}$ ) to 93.3 (genotype $\mathrm{A} \rightarrow \mathrm{B}$ ). This analysis included two sequences for each genotype hence inter-genotypic and intra-genotypic divergence was also determined. 
Table 3. Nucleotide sequence similarity and divergence of polymerase gene among HBV genotypes reference sequence obtained from NCBIGenBank database

\begin{tabular}{|c|c|c|c|c|c|c|c|c|c|c|c|c|c|c|c|c|c|}
\hline \multirow[b]{2}{*}{ 空 } & \multirow{2}{*}{\begin{tabular}{|c} 
Genotype \\
Accession number
\end{tabular}} & \multicolumn{2}{|c|}{$\mathrm{D}$} & \multicolumn{2}{|c|}{ G } & \multicolumn{2}{|c|}{ A } & \multicolumn{2}{|c|}{ B } & \multicolumn{2}{|c|}{$\mathrm{C}$} & \multicolumn{2}{|c|}{$\mathrm{E}$} & \multicolumn{2}{|c|}{$\mathrm{F}$} & \multicolumn{2}{|c|}{$\mathrm{H}$} \\
\hline & & 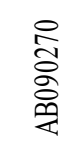 & $\frac{n}{\stackrel{n}{n}}$ & $\begin{array}{l}m \\
\frac{m}{0} \\
\text { के } \\
\text { qu }\end{array}$ & 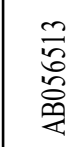 & 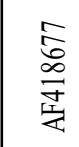 & $\frac{2}{\frac{2}{2}}$ & 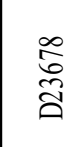 & $\begin{array}{l}\infty \\
\infty \\
\infty \\
\stackrel{2}{5} \\
\stackrel{2}{q}\end{array}$ & $\begin{array}{l}\text { के } \\
\stackrel{\circ}{+} \\
\text { ڤn }\end{array}$ & $\begin{array}{l}i \\
2 \\
\infty \\
\infty \\
\infty\end{array}$ & 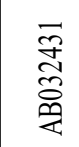 & $\begin{array}{l}\sqrt[n]{2} \\
\frac{n}{x}\end{array}$ & 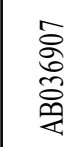 & 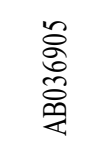 & \begin{tabular}{l}
$\stackrel{+}{5}$ \\
\multirow{2}{8}{} \\
$\stackrel{8}{2}$
\end{tabular} & 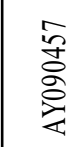 \\
\hline \multirow{2}{*}{ D } & AB090270 & & 97.7 & 88.9 & 89.2 & 90.5 & 91.5 & 88.8 & 88.9 & 86.9 & 87.5 & 90.2 & 91.4 & 84.1 & 84.1 & 83.2 & 83.9 \\
\hline & AF 151735 & 2.3 & & 87.9 & 88.2 & 89.3 & 89.6 & 86.9 & 86.9 & 84.5 & 85.2 & 89.6 & 90.2 & 83.8 & 83.8 & 82.6 & 83.2 \\
\hline \multirow{2}{*}{ G } & AB064313 & 11.1 & 12.1 & & 99.7 & 89.3 & 89.3 & 89.2 & 88.6 & 86.3 & 86.7 & 88.6 & 88.6 & 81.7 & 81.7 & 82.1 & 82.5 \\
\hline & AB056513 & 10.8 & 11.8 & 0.3 & & 89.6 & 89.6 & 89.6 & 88.9 & 86.4 & 87.0 & 88.3 & 88.9 & 82.1 & 82.1 & 82.5 & 82.9 \\
\hline \multirow{2}{*}{ A } & AF4 18677 & 9.5 & 10.7 & 10.7 & 10.4 & & 96.6 & 92.7 & 92.7 & 90.5 & 90.2 & 91.8 & 93.4 & 85.5 & 85.5 & 85.3 & 85.6 \\
\hline & X51970 & 8.5 & 10.4 & 10.7 & 10.4 & 3.4 & & 93.3 & 93.3 & 90.2 & 89.8 & 91.2 & 92.7 & 85.5 & 85.5 & 85.9 & 86.3 \\
\hline \multirow{2}{*}{ B } & D23678 & 11.2 & 13.1 & 10.8 & 10.4 & 7.3 & 6.7 & & 98.3 & 91.1 & 90.5 & 90.2 & 91.8 & 83.7 & 83.7 & 84.4 & 84.7 \\
\hline & AB073838 & 11.1 & 13.1 & 11.4 & 11.1 & 7.3 & 6.7 & 1.7 & & 91.1 & 90.8 & 90.2 & 91.8 & 83.7 & 83.7 & 84.8 & 85.1 \\
\hline \multirow{2}{*}{ C } & D50489 & 13.1 & 15.5 & 13.7 & 13.6 & 9.5 & 9.8 & 8.9 & 8.9 & & 97.5 & 88.9 & 89.9 & 82.8 & 82.8 & 82.0 & 82.3 \\
\hline & Y18855 & 12.5 & 14.8 & 13.3 & 13.0 & 9.8 & 10.2 & 9.5 & 9.2 & 2.5 & & 87.6 & 88.9 & 83.2 & 83.2 & 81.6 & 82.0 \\
\hline \multirow{2}{*}{$\mathrm{E}$} & AB032431 & 9.8 & 10.4 & 11.4 & 11.7 & 8.2 & 8.8 & 9.8 & 9.8 & 11.1 & 12.4 & & 97.4 & 84.1 & 84.1 & 82.9 & 82.9 \\
\hline & X75657 & 8.6 & 9.8 & 11.4 & 11.1 & 6.6 & 7.3 & 8.2 & 8.2 & 10.1 & 11.1 & 2.6 & & 84.8 & 84.8 & 83.6 & 84.3 \\
\hline \multirow{2}{*}{$\mathrm{F}$} & AB036907 & 15.9 & 16.2 & 18.3 & 17.9 & 14.5 & 14.5 & 16.3 & 16.3 & 17.2 & 16.8 & 15.9 & 15.2 & & 100.0 & 89.6 & 90.2 \\
\hline & AB036905 & 15.9 & 16.2 & 18.3 & 17.9 & 14.5 & 14.5 & 16.3 & 16.3 & 17.2 & 16.8 & 15.9 & 15.2 & 0.0 & & 89.6 & 90.2 \\
\hline \multirow{2}{*}{$\mathrm{H}$} & AY090454 & 16.8 & 17.4 & 17.9 & 17.5 & 14.7 & 14.1 & 15.6 & 15.2 & 18.0 & 18.4 & 17.1 & 16.4 & 10.4 & 10.4 & & 99.4 \\
\hline & AY090457 & 16.1 & 16.8 & 17.5 & 17.1 & 14.4 & 13.7 & 15.3 & 14.9 & $\mid 17.7$ & 18.0 & 17.1 & 15.7 & 9.8 & 9.8 & 0.6 & \\
\hline
\end{tabular}

\section{Evolutionary substitution rates}

All sequences were distributed under five different Gamma categories based on the sequence divergence and types of substitutions. Mean evolutionary rates in these categories were $0.00,0.05,0.25,0.90,3.80$ substitutions per site. The nucleotide frequencies were $\mathrm{A}=25.03 \%, \mathrm{~T}$ $=34.81 \%, \mathrm{C}=19.43 \%$, and $\mathrm{G}=20.73 \%$. For estimating ML values, a tree topology was automatically computed. The maximum Log likelihood for this computation was -2972.224. The estimated value of the shape parameter for the discrete Gamma Distribution is 0.2961. These nucleotide substitution rates are scaled such that the average evolutionary rate across all sites is 1 . This means that sites showing a rate $<1$ are evolving slower than average. $\mathrm{Nu}-$ cleotide positions with substitution rate less than 1 (Mean (relative) evolutionary rate $<1$ ) were $237 / 336$ whereas the number of sites with $>1$ substitution rate (Mean (relative) evolutionary rate $>1$ ) were $99 / 336$. Hence the sequence studied has $29.46 \%$ nucleotide positions which are evolving faster than average.

\section{HBV drug resistance interpretation}

Genotypic resistance mutations against lamivudine (L180M, M204V/I), adefovir (A181T, N236S), and entecavir (I169M, A184T/V, S202I/G, M250V/I/L) were not detected in any patient. Genotypic variants were detected as other mutations that may not be responsible for drug resistance. The mutations with greater than $5 \%$ incidence rate in study population have been provided along with their frequency in Table 4. Mutation at $248^{\text {th }}$ amino acid $(\mathrm{N} 248 \mathrm{H})$ of DNA polymerase gene was the most common genotypic variant found in $32.65 \%$ (32/98) of population. 


\section{Table 4. The mutations in HBV polymerase gene of study samples with greater than $5 \%$ incidence rate}

\begin{tabular}{|l|l|}
\hline Mutation Site & Number of patients with mutation (\% Rate) \\
\hline N248H & $32(32.65)$ \\
\hline I253V, D263E & $16(16.33)$ \\
\hline E271D, V253I & $10(10.20)$ \\
\hline Q267L, I266R & $7(7.14)$ \\
\hline I282V, N226H, S213T, I266T, S219A & $6(6.12)$ \\
\hline Q267H, C256G, N238H, D263S & $5(5.10)$ \\
\hline
\end{tabular}

\section{Discussion}

Traditional HBV genotyping methods using restriction fragment length polymorphism (RFLP) have been developed and used extensively for HBV genotypes A to $\mathrm{H} .{ }^{20}$ Genotyping methods that use multiplex PCR with type-specific primers have also been reported. ${ }^{13}$ However, most of these newer methods are based on analyzing the $S$ gene. Here we employed genotyping method based on a segment of the HBV DNA polymerase gene.

This study demonstrated that using HBV DNA polymerase gene sequence all the different genotypes show distinct clades in phylogenetic analysis and hence the gene fragment used for analysis is a suitable target for HBV genotyping. As evident from phylogenetic tree, based on the clusters formed by genotypes A-H, the sequences obtained from HBV DNA polymerase gene from patients can be classified under these genotypes.

In this study, the predominant genotype of Hepatitis B was found to be genotype $\mathrm{D}$, and there were no patients with drug resistant HBV. As per previous reports, genotype $\mathrm{C}$ is less reported in India, however we found 18 out of 98 cases to be genotype $\mathrm{C}$ which indicates substantial increase in infections with genotype $\mathrm{C}$ in Indian population. ${ }^{21}$ The variation in relative frequency of HBV genotypes reported in studies from India by various authors have confirmed that the genotype $\mathrm{D}$ has been predominant among others. ${ }^{22}$ Therefore, the fragment of HBV DNA polymerase gene as a target for genotyping hepatitis B in India has been proved to be significant. This genotyping method can also be used to predict antiviral therapeutic response among HBV genotypes and the development of drug resistance due to mutations. The fragment covers clinically important YMDD domain of polymerase gene, mutations which are responsible for failure of anti-viral therapy. Hence using the same se- quence data, interpretation of drug resistance in $\mathrm{HBV}$ is possible. It is a valuable tool for guiding the treatment of lamivudine-resistant $\mathrm{HBV}$ in different clinical settings. ${ }^{23}$ Nucleotide sequence analysis of HBV DNA polymerase gene in all patient samples using different genotyping algorithms detected genotypes $\mathrm{A}, \mathrm{C}$ and $\mathrm{D}$ whereas genotypes B, E, F, G and $\mathrm{H}$ were not detected.

Of the eight genotypes of HBV, infection with HBV genotype $\mathrm{D}$ is the most common in India. Infection with genotype $\mathrm{D}$ is associated with more severe liver disease than genotype A. ${ }^{24}$ The major route of HBV transmission in acute hepatitis seem to be sexual intercourse, frequent international travel and contact with people from different ethnic backgrounds, which may contribute to change in the predominance pattern of genotypes in a geographical location. ${ }^{25}$ This study demonstrated that the patients suffering from HBV infection were infected with different genotypes as D, C and A, suggesting no significant change in predominance of HBV genotype in hepatitis B infected cases.

Drug resistant viral strains are evolved due to increased use of anti-viral drugs to treat chronic hepatitis B, such as lamivudine, adefovir, telbivudine, and entecavir. ${ }^{26}$ In absence of anti-viral drugs and drug pressure, most of the drug resistant mutants do not survive and may not remain as fit as the wild type virus in an acutely infected liver. ${ }^{27,28}$ In contrast, natural resistance mutations in treatment-naive chronic hepatitis B patients may exist. Mutation substitution rates in polymerase gene as per our study reveal the number of nucleotide position which are more prone to mutations indicating that such changes may drive incidence of drug resistance as well as different genotypes. Our study was limited to genotype D, C and A due to non-availability of samples from other genotypes, larger studies that include samples from patients with all HBV genotypes are required to represent data for all genotypes. 


\section{Conclusion}

The study reports Hepatitis B Virus genotyping using DNA polymerase gene fragment sequencing as an effective tool to determine the HBV genotypes as well as drug resistance mutations in $\mathrm{HBV}$ infected patients. This study reports high prevalence of genotype $\mathrm{D}$ which is in concordance with previous studies. It provides a useful alternative to complete sequencing of the HBV genome and allows the study genetic variation between various genotypes and drug resistance mutations responsible for anti-viral drug failure. Genotyping data of $\mathrm{HBV}$ via sequence of DNA polymerase fragment from various geographical population can be generated to validate this method in different populations. One of the studies reported from China demonstrated the significance of HBV DNA polymerase gene sequencing based genotyping and drug resistance interpretation. ${ }^{10}$ Future studies in patients at different stages of infection and therapeutic treatment would help us in understanding the relevance of genotype, resistance mutations and response of the patient to a particular therapy. These studies can be carried out to investigate the clinical, virological and therapeutical response characteristics of HBV genotypes, with clinical data such that the status of HBV infection can be characterized (carrier, immunotolerant, acute and chronic hepatitis, cirrhosis) using a large population size.

\section{Acknowledgement}

Authors are thankful to Mr. Hrishikesh Joshi from GeneSupport (India) for writing and proof reading assistance during preparation of the manuscript.

\section{Abbreviations}

CHB - Chronic Hepatitis B

SVR - Sustained viral response

\section{Conflict of interest}

Authors declare no conflict of interest.

\section{References}

1. Kumar A, Dwivedi M, Misra SP, Narang S, Tiwari BK, Pandey R. Clinical profile, genotype and management updates of hepatitis B virus. Indian J Virol 2011;22:1-10.

2. Andernach IE, Hubschen JM, Muller CP. Hepatitis B virus: the genotype E puzzle. Rev Med Virol 2009;19:231240.

3. Yousif M, Kramvis A. Genotype D of hepatitis B virus and its subgenotypes: An update. Hepatol Res 2013;43:355-364.

4. Qin Y, Tang X, Garcia T, Hussain M, Zhang J, Lok A, et al. Hepatitis $B$ virus genotype $C$ isolates with wild-type core promoter sequence replicate less efficiently than genotype $\mathrm{B}$ isolates but possess higher virion secretion capacity. J Virol 2011;85:10167-10177.

5. Tsubota A, Arase Y, Ren F, Tanaka H, Ikeda K, Kumada H. Genotype may correlate with liver carcinogenesis and tumor characteristics in cirrhotic patients infected with hepatitis B virus subtype adw. J Med Virol 2001;65:257-265.

6. Cao GW. Clinical relevance and public health significance of hepatitis B virus genomic variations. World J Gastroenterol 2009;15:5761-9.

7. Kobayashi M, Arase Y, Ikeda K, Tsubota A, Suzuki Y, Saitoh S, et al. Clinical characteristics of patients infected with hepatitis B virus genotypes A, B, and C. J Gastroenterol 2002;37:35-39.

8. Mayerat C, Mantegani A, Frei PC. Does hepatitis B virus (HBV) genotype influence the clinical outcome of HBV infection? J Viral Hepat 1999;6:299-304. PubMed

9. Thakur V, Sarin SK, Rehman S, Guptan RC, Kazim $\mathrm{SN}$, Kumar S. Role of HBV genotype in predicting response to lamivudine therapy in patients with chronic hepatitis B. Indian J Gastroenterol 2005;24:12-15.

10. Ma Y, Ding Y, Juan F, Dou XG. Genotyping the hepatitis $B$ virus with a fragment of the HBV DNA polymerase gene in Shenyang, China. Virol J 2011;8:315.

11. Yeh SH, Tsai CY, Kao JH, Liu CJ, Kuo TJ, Lin MW, et al. Quantification and genotyping of hepatitis B virus in a single reaction by real-time PCR and melting curve analysis. J Hepatol 2004;41:659-666.

12. Larkin MA, Blackshields G, Brown NP, Chenna R, McGettigan PA, McWilliam H, et al. Clustal W and Clustal X version 2.0. Bioinformatics 2007;23:2947-2948.

13. Chen J, Yin J, Tan X, Zhang H, Zhang H, Chen B, et al. Improved multiplex-PCR to identify hepatitis $B$ virus genotypes A-F and subgenotypes B1, B2, C1 and C2.J Clin Virol 2007;38:238-243.

14. Lusida MI, Nugrahaputra VE, Soetjipto Handajani R, Nagano-Fujii M, Sasayama M, et al. Novel subgenotypes of hepatitis B virus genotypes C and D in Papua, Indonesia. J Clin Microbiol 2008;46:2160-2166.

15. Tamura K, Stecher G, Peterson D, Filipski A, Kumar S. MEGA6: Molecular Evolutionary Genetics Analysis version 6.0. Mol Biol Evol 2013;30:2725-2729. 
16. Felsenstein J. Estimating effective population size from samples of sequences: a bootstrap Monte Carlo integration method. Genet Res 1992;60:209-220.

17. Fares MA, Holmes EC. A revised evolutionary history of hepatitis B virus (HBV). J Mol Evol 2002;54:807-814.

18. Tamura K, Nei M. Estimation of the number of nucleotide substitutions in the control region of mitochondrial DNA in humans and chimpanzees. Mol Biol Evol 1993;10:512-526.

19. Tamura K, Kumar S. Evolutionary distance estimation under heterogeneous substitution pattern among lineages. Mol Biol Evol 2002;19:1727-1736.

20. Zeng GB, Wen SJ, Wang ZH, Yan L, Sun J, Hou JL. A novel hepatitis $B$ virus genotyping system by using restriction fragment length polymorphism patterns of $\mathrm{S}$ gene amplicons. World J Gastroenterol 2004;10:3132-3136. 21. Kumar A, Kumar SI, Pandey R, Naik S, Aggarwal R. Hepatitis $B$ virus genotype $A$ is more often associated with severe liver disease in Northern India than is genotype D. Indian J Gastroenterol 2005;24:19-22.

22. Gandhe SS, Chadha MS, Arankalle VA. Hepatitis B virus genotypes and serotypes in Western India: lack of clinical significance. J Med Virol 2003;69:324-330.
23. Pan XP, Li LJ, Du WB, Li MW, Cao HC, Sheng JF. Differences of YMDD mutational patterns, precore/ core promoter mutations, serum HBV DNA levels in lamivudine-resistant hepatitis B genotypes B and C. J Viral Hepat 2007;14:767-774.

24. Amini-Bavil-Olyaee S, Hosseini SY, Sabahi F, Alavian SM. Hepatitis B virus (HBV) genotype and YMDD motif mutation profile among patients infected with HBV and untreated with lamivudine. Int J Infect Dis 2008;12:83-87. 25. Te HS, Jensen DM. Epidemiology of hepatitis B and C viruses: a global overview. Clin Liver Dis 2010;14:1-21. 26. Yim HJ, Hussain M, Liu Y, Wong SN, Fung SK, Lok AS. Evolution of multi-drug resistant hepatitis B virus during sequential therapy. Hepatology 2006;44:703-712. 27. Liu Y, Wang CM, Cheng J, Liang ZL, Zhong YW, Ren $X Q$, et al. Hepatitis B virus in tenofovir-naive Chinese patients with chronic hepatitis $\mathrm{B}$ contains no mutation of rtA194T conferring a reduced tenofovir susceptibility. Chin Med J (Engl) 2009;122:1585-1586.

28. Zoulim F, Locarnini S. Hepatitis B virus resistance to nucleos(t)ide analogues. Gastroenterology 2009;137:15931608 e1-2. 